\title{
Benign clear cell "sugar" tumor of the lung in a patient with Birt-Hogg-Dubé syndrome: a case report
}

Yoko Gunji-Niitsu ${ }^{1,8}$, Toshio Kumasaka ${ }^{2,8}$, Shigehiro Kitamura ${ }^{3}$, Yoshito Hoshika ${ }^{1,8}$, Takuo Hayashi ${ }^{4,8}$, Hitoshi Tokuda ${ }^{5}$, Riichiro Morita ${ }^{6}$, Etsuko Kobayashi ${ }^{1,8}, K^{2}$ Keiko Mitani ${ }^{4,8}$, Mika Kikkawa $^{7}$, Kazuhisa Takahashi ${ }^{1}$ and Kuniaki Seyama ${ }^{1,8^{*}}$ (I)

\begin{abstract}
Background: Birt-Hogg-Dubé (BHD) syndrome is a rare inherited autosomal genodermatosis and caused by germline mutation of the folliculin (FLCN) gene, a tumor suppressor gene of which protein product is involved in mechanistic target of rapamycin (mTOR) signaling pathway regulating cell growth and metabolism. Clinical manifestations in BHD syndrome is characterized by fibrofolliculomas of the skin, pulmonary cysts with or without spontaneous pneumothorax, and renal neoplasms. There has been no pulmonary neoplasm reported in BHD syndrome, although the condition is due to deleterious sequence variants in a tumor suppressor gene. Here we report, for the first time to our knowledge, a patient with BHD syndrome who was complicated with a clear cell "sugar" tumor (CCST) of the lung, a benign tumor belonging to perivascular epithelioid cell tumors (PEComas) with frequent causative relation to tuberous sclerosis complex 1 (TSC1) or 2 (TSC2) gene.
\end{abstract}

Case presentation: In a 38-year-old Asian woman, two well-circumscribed nodules in the left lung and multiple thin-walled, irregularly shaped cysts on the basal and medial area of the lungs were disclosed by chest roentgenogram and computer-assisted tomography (CT) during a preoperative survey for a bilateral faucial tonsillectomy. Analysis of the resected tumor showed large polygonal cells with clear cytoplasm proliferating in a solid pattern. Immunohistochemistry revealed that these tumor cells were positive for microphthalmia-transcription factor, S100, and CD1a but negative for HMB45, indicating that the tumor was a CCST. Genetic testing indicated that the patient had a germline mutation on exon 12 of the FLCN gene, i.e., insertion of 7 nucleotides (CCACCCT) (c.1347_1353dupCCACCCT). Direct sequencing of the FLCN exon 12 using genomic DNA obtained from her microdissected CCST cells clearly revealed loss of the wild-type FLCN sequence, which confirmed complete functional loss of the FLCN gene. On the other hand, no loss of heterozygosity around TCS1- or TSC2-associated genetic region was demonstrated.

Conclusion: To our knowledge, this is the first report of CCST of the lung in a patient with BHDS, indicating that CCST should be added to the spectrum of pulmonary manifestations of BHDS.

Keywords: Folliculin, Loss of heterozygosity, Tumor suppressor gene syndrome, Germline mutation

\footnotetext{
* Correspondence: kseyama@juntendo.ac.jp

'Divisions of Respiratory Medicine, Juntendo University Faculty of Medicine and Graduate School of Medicine, 3-1-3, Hongo, Bunkyo-Ku, Tokyo 113-8431, Japan

${ }^{8}$ The Study Group of Pneumothorax and Cystic Lung Diseases, 4-8-1 Seta,

Setagaya-Ku, Tokyo 158-0095, Japan

Full list of author information is available at the end of the article
} 


\section{Background}

Birt-Hogg-Dubé (BHD) syndrome is a rare inherited autosomal genodermatosis originally reported by Hornstein and Knickenberg in 1975 [1] and by three Canadian doctors (Birt, Hogg, and Dubé) in 1977 [2]. BHD syndrome is caused by mutations of the FLCN gene, which codes a protein called folliculin and functions as a tumor suppressor gene $[3,4]$. Several tumor-suppressor genes are linked to hamartoma syndromes through the convergent energy/nutrient-sensing pathways involved in the mechanistic target of rapamycin (mTOR) signaling, especially mTOR complex1 (mTORC1) [5-7]: TSC1 and TSC2 being responsible for tuberous sclerosis complex (TSC) [8], LKB1 for PeutzJeghers syndrome [9], and PTEN for Cowden syndrome [10]. Since mTORC1 is strongly related to cell growth, proliferation, and metabolism, hamartoma syndromes are characterized by an increased risk of the development of benign as well as malignant neoplasms. BHD syndrome is one such hamartoma syndrome. Recent studies have shown the close association of folliculin with the mTORC1 signaling pathway; folliculin acts as a GTPase-activating-protein for RagC/ D to recruit mTORC1 to lysosomes where mTORC1 exerts its function [11]. Accordingly, patients with BHD syndrome are at risk of developing neoplasms in skin (fibrofolliculoma) and kidneys (renal cell carcinoma), colon carcinoma, or other tumors. However, no pulmonary tumor associated with BHD syndrome has been reported to date.

Clear cell "sugar" tumor (CCST) of the lung is a rare benign tumor originally reported in 1971 by Liebow and Castleman, who noted its resemblance to metastases of clear renal cell carcinomas [12]. CCSTs belong to a family of perivascular epithelioid cell tumors (PEComas) that are defined by their morphologically and immunohistochemically distinctive perivascular epithelioid vascular cells and arise at a variety of visceral and soft tissue sites [13]. PEComas include angiomyolipomas [14] and lymphangioleiomyomatosis [15], both being the representative disorders related to TSC. Actually, the genetic and molecular bases of PEComas appear to be aberrations on chromosome 16 and at the TSC 2 locus resulting in activation of the mTOR pathway [16].

We herein describe a patient with BHD syndrome who developed CCST of the lung. We demonstrated that this patient's CCST entailed complete functional loss of FLCN without TSC2 loss of heterozygosity ( $\mathrm{LOH})$, supporting the presumption that TSC1/2 and FLCN share the mechanism for their tumorigenesis.

\section{Case presentation}

A solitary pulmonary nodule measuring $25 \mathrm{~mm}$ in diameter was found in the left lung of a 38-year-old female whose chest roentgenogram (Fig. 1a) underwent preoperative assessment in January 2006 during preparation for a bilateral faucial tonsillectomy due to recurrent tonsillitis. The computer-assisted tomography (CT) of the chest showed two well-circumscribed nodules (approximately 25 and $5 \mathrm{~mm}$ in diameter, respectively) without apparent contrast enhancement in the lower, left lobe (Fig. $1 \mathrm{~b}$ and $\mathrm{c}$ ). In addition to the nodules, multiple thin-walled, irregularly shaped cysts were distributed

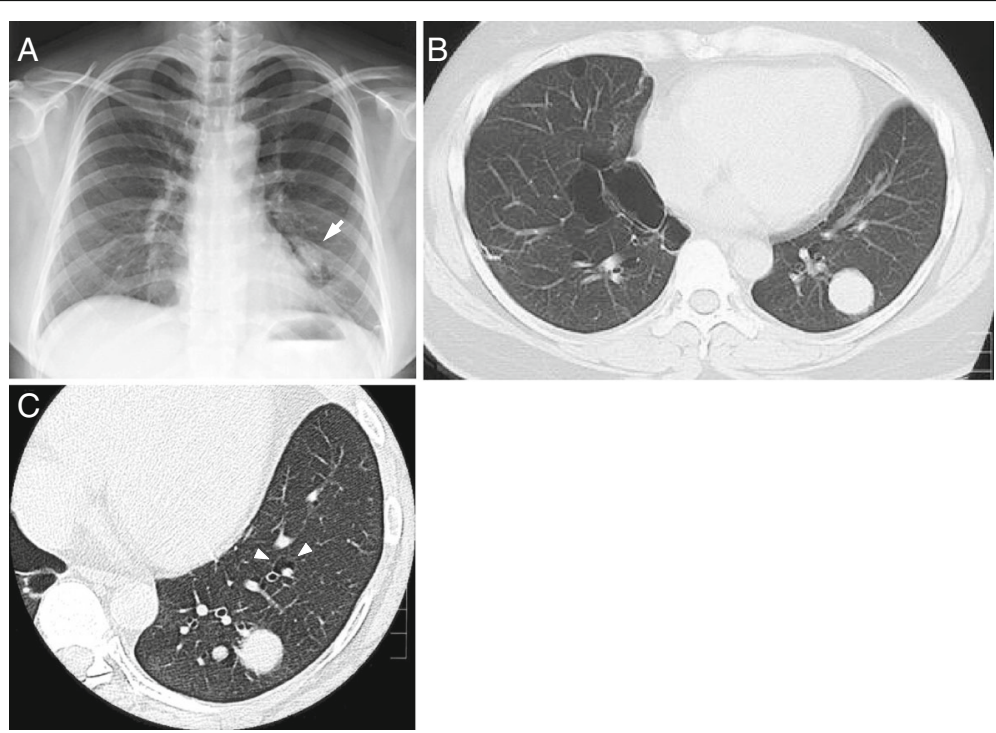

Fig. 1 Plain radiograph and computed tomography of the chest. Plain chest radiograph on admission showed a nodular shadow superimposed on the edge of a cardiac silhouette (a). Computed tomography of the chest demonstrated a round nodule (the larger nodule, 25 mm in diameter) with a clear margin in the lower, left lobe and multiple irregularly shaped cysts in the bilateral lower lobes (b). Another axial image showed a smaller nodule (5 $\mathrm{mm}$ in diameter) having a similar characteristics with the larger nodule (c). Note that a small cyst abutting a pulmonary artery (white arrowheads) 
predominantly on the basal and medial areas of the lungs (Fig. 1b and c). She was asymptomatic, and physical examinations found no abnormalities. She was an ex-smoker but to the very mild degree of 0.6 pack-year. However, her past medical history was remarkable. Vocal cord nodules were resected when she was 25-, 26-, and 27years-old; three episodes of spontaneous pneumothorax (PTX) occurred at the ages of 26, 27, and 30 years (chest tube drainage for left PTX at 26-years-old, and operations were performed for a right PTX at 27- and for left PTX at 30-years-old). The resection of multiple uterine myomas followed when she reached 30 years of age, and the leftsided thyroid gland was extirpated to remove a welldifferentiated papillary adenocarcinoma when she was 32years-old. The family history taken from interviews with the patient and her mother was extraordinary in terms of PTX events and neoplasms (Fig. 2). Her mother (III-2 in Fig. 2) had experienced spontaneous PTX and renal cancer (no detailed information on histological type), and the maternal grandmother (II-2 in Fig. 2) had undergone a spontaneous PTX. Fibrofollicuoma-like papules were noted on faces and necks of both the patient (IV-1 in Fig. 2) and her mother, but were not mentioned for any other family members during their interviews. Later, we confirmed by CT of the chest that the mother had multiple pulmonary cysts with characteristic features similar to those of the index case.

For the patient described here, a CT-guided needle biopsy of the left pulmonary nodule (the larger nodule) was performed to determine a diagnosis. Pathological examination revealed that it was a clear cell carcinoma of undetermined origin. No clear cell carcinoma of the kidney was identified by magnetic resonance imaging. Ultrasonography of the thyroid gland showed no abnormalities. Subsequently, on February 28, 2006, a left lower lobectomy was performed. The left hilar lymph node was negative for metastasis, and no further resection of mediastinal lymph nodes was performed. Neither recurrence nor metastasis has been found since then or up to the writing of this case report in 2015.

\section{Materials and methods}

Histopathologic and immunohistochemical examinations

The patient's resected lung tissues were fixed in 10\% buffered formalin, embedded in paraffin after routine processing, and stained with hematoxylin and eosin (H\&E). Immunostaining was performed with antibodies directed to the following: vimentin (dilution 1:400, Dako Cytomation, Carpinteria, CA, USA), cytokeratin (dilution 1:200, Immunotech, Malseille, France), $\alpha$-smooth muscle actin $(\alpha$-SMA) (dilution 1:200, Dako Cytomation), HMB45 (dilution 1:200, Dako Cytomation), Melan-A (dilution 1:50, Dako Cytomation), PNL-2 (dilution 1:200, Dako Cytomation), microphthalmia-associated transcription factor (dilution 1:50, Leica Biosystems, New Castle, UK), S100 (dilution 1:300, Dako Cytomation), CD1a (dilution 1:100, Dako Cytomation, clone O10), CD10 (dilution 1:100, Dako Cytomation), CD63 (dilution 1:400, Chemicon, Temecula, CA, USA), and folliculin (dilution 1:150, Santa Cruz, Paso Robles, CA, USA). An EnVision Dual LINK system-HRP (a polymer-based detection system, Dako Cytomation) was used to detect binding of the first antibodies according to the manufacturer's instructions,

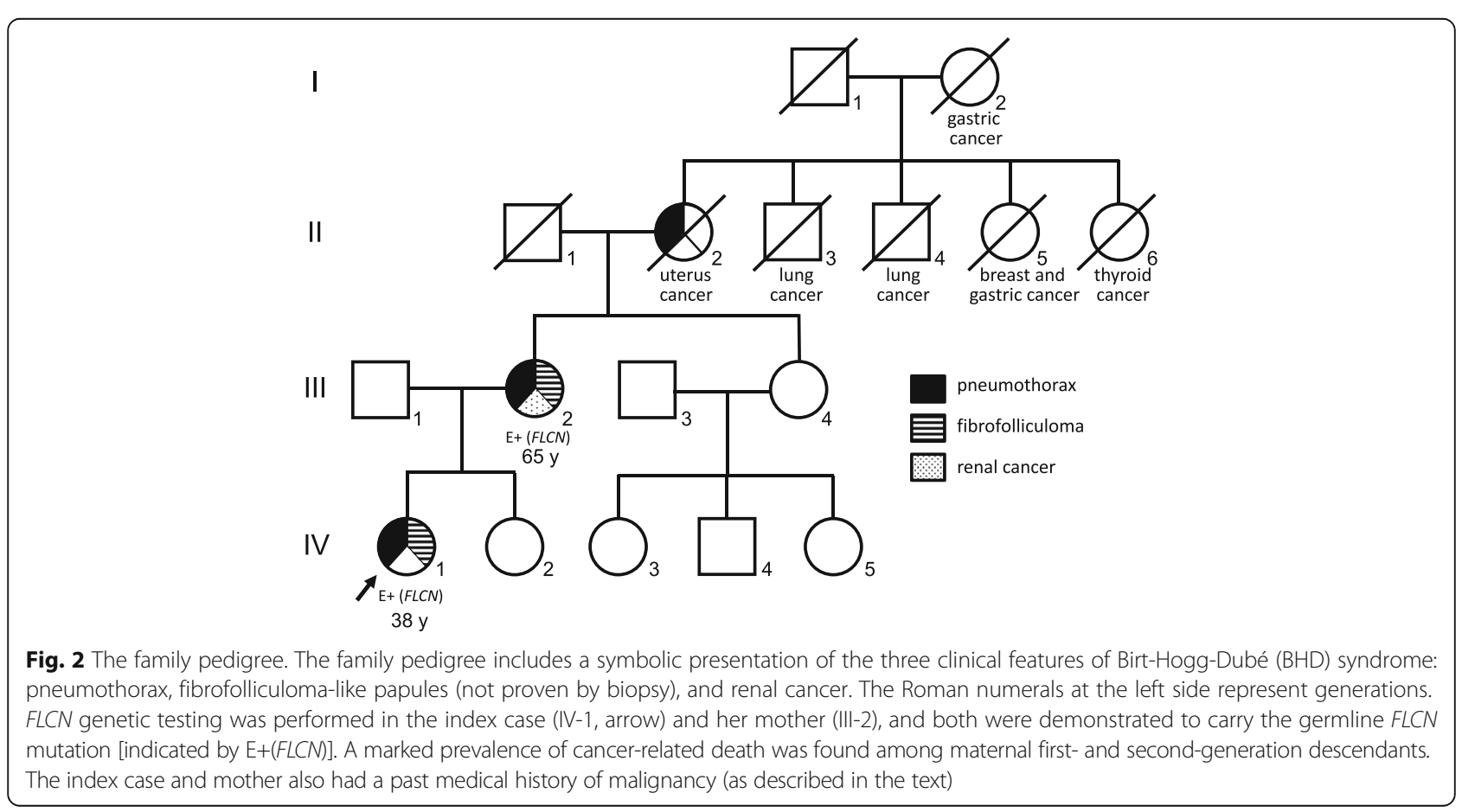


and 3, 3'-diaminobenzidine tetrahydrochloride was used as the chromogen.

\section{Mutation analysis of the FLCN gene and LOH analysis of the $F L C N$ gene-associated region}

Genomic DNA isolated from peripheral blood leukocytes was utilized to identify a germline $F L C N$ mutation according to the method described previously [17]. Briefly, each exon of the $F L C N$ gene was separately amplified and then screened by denaturing high-performance liquid chromatography. When a mobility shift was detected, sequencing of the exon of concern was performed using an automated sequencer (ABI Prism BigDye Terminator v1.1 Cycle Sequencing kit and ABI 3130 Genetic Analyzer; both Applied Biosystems, Foster City, CA, USA). Cloning of the PCR product was performed using a TA cloning kit (Invitrogen ${ }^{\mathrm{TM}}$, Houston, TX, USA).

For LOH analysis of the FLCN gene-associated region (chromosome 17p12.2), tumor cells in a lung nodule were manually microdissected from an 8 - $\mu$ m-thick pathological specimen under an inverted microscope. Normal alveolar tissues were also microdissected as a control. Genomic DNA was extracted from the microdissected cells with $25 \mu \mathrm{l}$ extraction buffer consisting of $50 \mathrm{mM}$ Tris- $\mathrm{HCl}$ (pH8.0), $1 \mathrm{mM}$ EDTA, 0.5\% Tween 20, and 1/50 volume of proteinase $\mathrm{K}$ solution $(10 \mathrm{mg} / \mathrm{ml})$. Two microsatellite markers, D17S740 and D17S2196, were examined for LOH analysis according to the method described by Khoo et al. [18]; the FLCN gene is located on the genome between these two markers. The PCR products were electrophoresed using an Applied Biosystems 3130/3130xl Genetic Analyzer. LOH analysis was performed using Gene Mapper $^{\circ} 4.0$ (both from Applied Biosystems, Foster City, CA, USA). To confirm reproducibility, all lesions were examined at least twice. A reduction in signal intensity over 50\% was defined as $\mathrm{LOH}$.

\section{Results}

\section{Pathologic findings in pulmonary nodules}

The two tumors, measuring $25 \mathrm{~mm}$ and $5 \mathrm{~mm}$ in diameter, respectively, were clearly demarcated from lung parenchyma. They showed identical histopathological findings and consisted of large polygonal cells with clear cytoplasm in a solid pattern (Fig. 3a). A meshwork-like vasculature separated these tumor cells, some of which were small with round nuclei but others of larger size contained bizarre nuclei without hyperchromaticity. The cytoplasm stained readily with periodic acid-Schiff (PAS) (Fig. 3b), but neither mitosis nor vascular invasion was seen. Although the preoperative diagnosis was clear cell carcinoma of undetermined origin, that designation was then corrected to clear cell "sugar" tumor (CCST) of the lung, belonging to a family of PEComa [19]. The results of immunohistochemistry are summarized in Table 1. Analysis revealed that the tumor cells were immunopositive for vimentin, microphthalmia transcription factor (Fig. 3c), S100, CD1a (Fig. 3d), CD10 (Fig. 3e), CD63, and folliculin (Fig. 3f), but immunonegative for cytokeratin, $\alpha$-smooth muscle actin, HMB45, Melan-A, and PNL-2. Interestingly, immunopositivity for folliculin was stronger in the cytoplasm of large tumor cells with bizarre nuclei than in that of the small tumor cells with round nuclei (Fig. 3f). Additionally, there was no proliferation of lymphangioleiomyomatosis cells observed in the underlying lung parenchyma.

\section{Genetic diagnosis of BHD syndrome and LOH analysis}

Family history of pulmonary cysts/spontaneous PTX and renal tumors as well as characteristic radiologic features was strongly suggestive of BHD syndrome and prompted us to perform $F L C N$ genetic testing. Mutation analysis identified a germline mutation on exon 12 of the FLCN gene, an insertion of 7 nucleotides (CCACCCT) (c. c.1347_1353dupCCACCCT) (Fig. 4). The expected result would be a frame shift and premature termination of protein translation [p.(Val452Profs"457)], thereby establishing the diagnosis of BHD syndrome.

CCST showed LOH at both D17S740 and D17S2196 (Fig. 5). Direct sequencing of exon 12 using genomic DNA obtained from the patient's microdissected CCST cells (from the larger tumor) clearly revealed the loss of wild-type FCLN sequence (Fig. 4c), confirming the complete loss-offunction of the FLCN gene (Knudson's 2-hit theory). In contrast, none of the microsatellite markers on two TSC loci (TSC1 on chromosome 9q and TSC2 on chromosome 16) manifested LOH (data not shown).

\section{Discussion}

Our study reports, for the first time, a CCST of the lung in a patient with BHD syndrome. Additionally, no pulmonary neoplasm has been reported to date that was proved to have complete loss-of-function type FLCN mutation, hence meeting the Knudson's 2-hit theory. CCST of the lung belongs to a family of PEComas that is characterized by perivascular epithelioid cell differentiation and immunopositivity for both myoid and melanocytic immunohistochemical markers; a representative of the latter is HMB45. These immunohistochemical profiles are adjunctively important to differentiate CCST from renal cell carcinoma. However, the existence of HMB45-negative PEComas was reported [20-23]. We examined the expression of four different markers of the melanocytic lineage (HMB45, Melan-A, PNL-2, and microphthalmia-associated transcription factor) in our patient and found that, of those markers, only microphthalmia-associated transcription factor was immunopositive. Accordingly, based on both morphological appearance and immunohistochemical features, we diagnosed this patient with HMB45-negative CCST of the lung. 


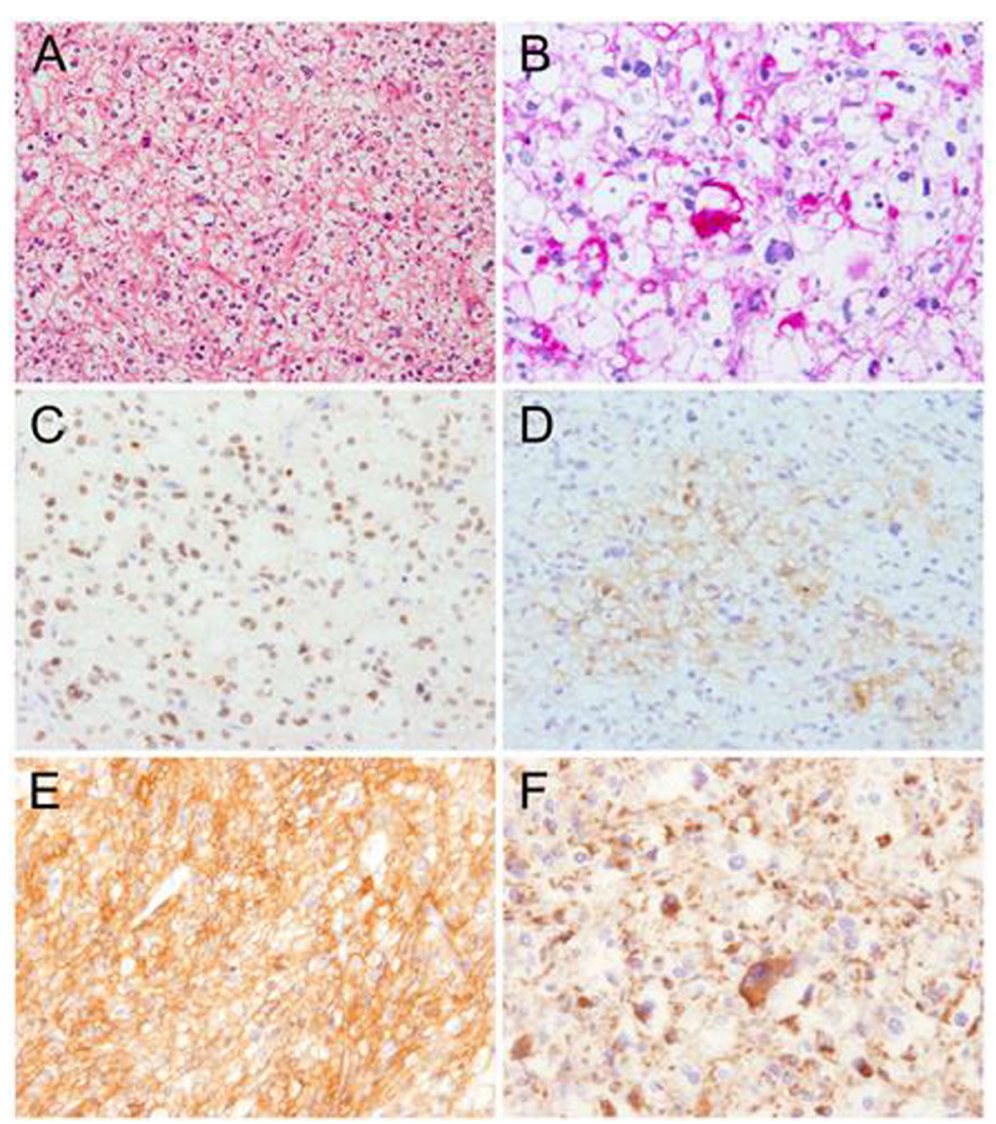

Fig. 3 Pathologic findings of a pulmonary nodule in the left lower lobe. The nodule consisted of polygonal tumor cells with pleomorphic nuclei and clear cytoplasm (a, H\&E). The PAS stain was intensively positive in cytoplasm of tumor cells (b). Immunohistochemistry revealed that nuclei of the tumor cells were diffusely positive for microphthalmia transcription factor (c), and their membrane was weakly positive for CD1a (d), strongly positive for CD10 (e), and focally positive for folliculin (f)

Table 1 Summary of immunoreactivity demonstrated in BirtHogg-Dubé syndrome-associated clear cell "sugar" tumor in the lung

\begin{tabular}{ll}
\hline Antibodies & Immunoreactivity \\
\hline Cytokeratin & - \\
Vimentin & + (Focally strong) \\
a-smooth muscle actin & - \\
HMB45 & - \\
Melan-A & - \\
PNL-2 & - \\
Microphthalmia transcription factor & + \\
S100 & + (Focally strong) \\
CD1a & + (Focally weak) \\
CD10 & + (Focally strong) \\
CD63 & + (Diffusely weak) \\
folliclin & + (Focally strong) \\
\hline
\end{tabular}

This is the first example described that associates the development of CCST with functional loss of FLCN. Interestingly, this woman's test results document a stronger immunopositivity for folliculin in the cytoplasm of large tumor cells with bizarre nuclei than in that of small tumor cells with round nuclei. Still unclear is whether the immunoreactivity we detected for polyclonal anti-folliculin antibody implies a causative role of mutated folliculin in the tumorigenesis of CCST or merely nonspecific binding. As is well-known, the development of PEComas is closely associated with dysregulated mTORC1 activity, which is often due to a functional loss of TSC1 or TSC2. Although the function of folliculin is not fully understood, folliculin and mTORC1 are considered to be functionally related in the cellular signaling pathway; i.e., folliculin acts as a GTPase-activating-protein for RagC/D for the recruitment of mTORC1 to lysosomes, where mTORC1 exerts its function [11, 24]. Recently, a distinct subset of PEComas was reported to harbor a TFE3 gene fusion [20]. Interestingly, these tumors are immunopositive for TFE3, but negative for markers of the melanocyte lineage, such as 


\section{A. genome isolated from leukocytes}

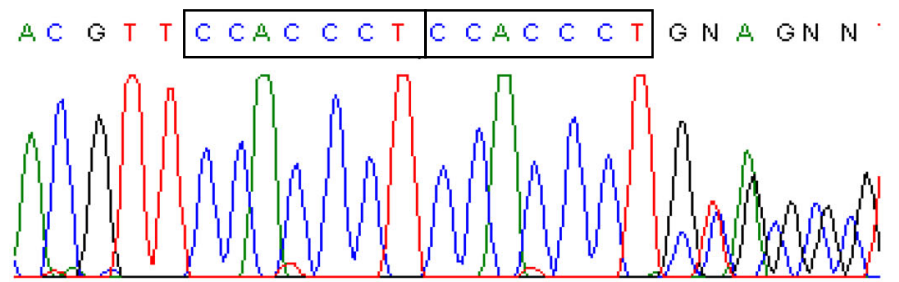

\section{B. cloning of PCR products}
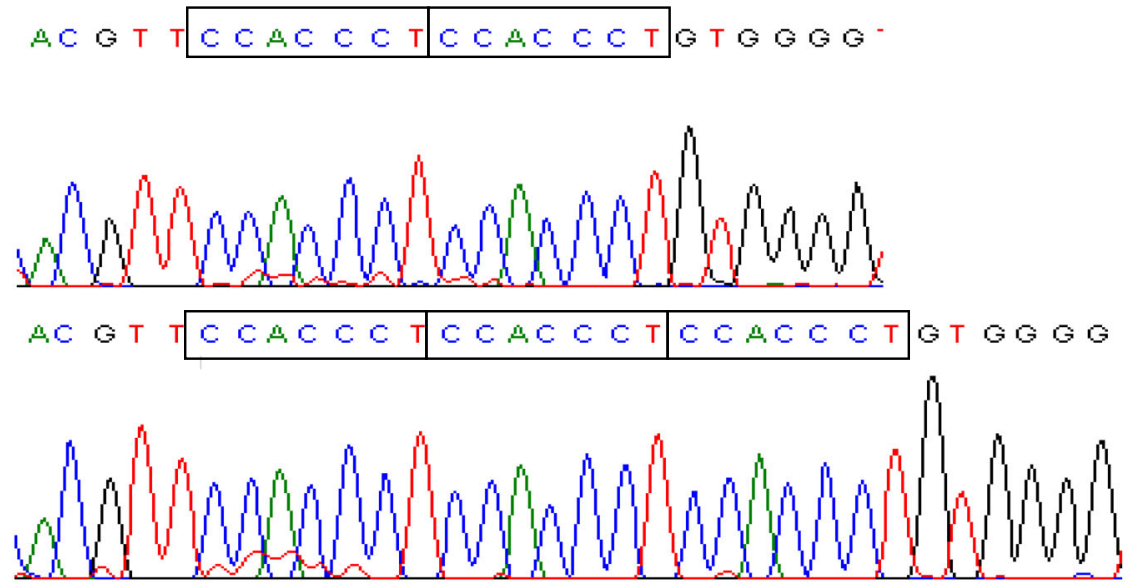

\section{C. genome of microdissected tumor cells}

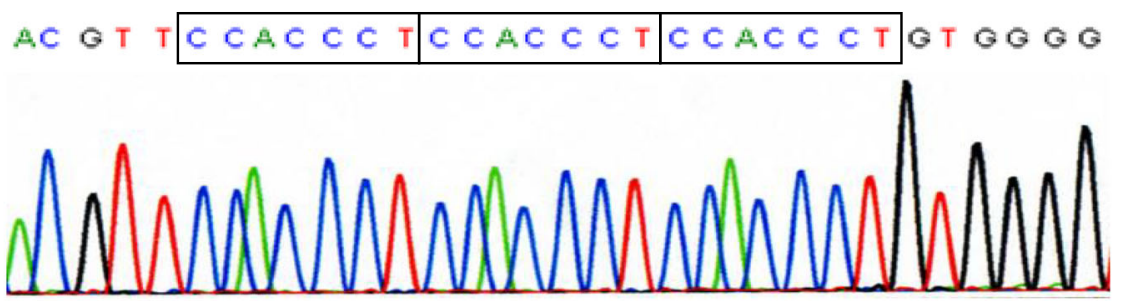

Fig. 4 Mutation analysis of the FLCN gene. Sequencing of exon 12 of the FLCN gene demonstrated a superimposed sequence after the CCACCCT repeat when genomic DNA isolated from the index case's peripheral blood leukocytes was used as a template (a). Cloning of the PCR product of exon 12 identified clones carrying the wild-type sequence and those carrying an insertion of 7 nucleotides (CCACCCT) (c.1347_1353dupCCACCCT), resulting in a frame shift and premature termination of protein translation (b). In contrast, only the mutated sequence with a 7-nucleotide insertion was demonstrated when genomic DNA isolated from microdissected tumor cells was utilized as a template (c)

microphthalmia-associated transcription factor, Mart-1, and HMB45. The CCST in our patient showed no immunoreactivity for TFE3 (data not shown). Variability of immunostaining results regarding cell-lineage markers may be related to the uncertainty of CCST's cellular origin [19]. However, the CCST described here showed membranous immunopositivity for CD1a, a useful marker for Langerhans cells, as Adachi et al. previously reported [25].

Clinically notable in the family of our patient are the many deaths from cancer in the maternal ancestors (Fig. 2). Multiple occurrences of neoplasms at various sites including uterus, thyroid, vocal cord, and the lung in the index case are also remarkable. Although FLCN is considered to function as a tumor-suppressor gene, the established propensity for cancer in BHD syndrome so far is limited to the renal neoplasms [26-28]; whether BHD syndrome confers the risk of developing colorectal cancer remains conjectural [29]. We previously reported that the de novo FLCN mutation occurred in descendents of patients with familial adenomatous polyposis [30], a disease caused by germline mutation of the APC gene. Historically, BHD syndrome was first identified in a family who developed hereditary medullary carcinoma of the thyroid, a disease now recognized as a tumor-suppressor gene syndrome 


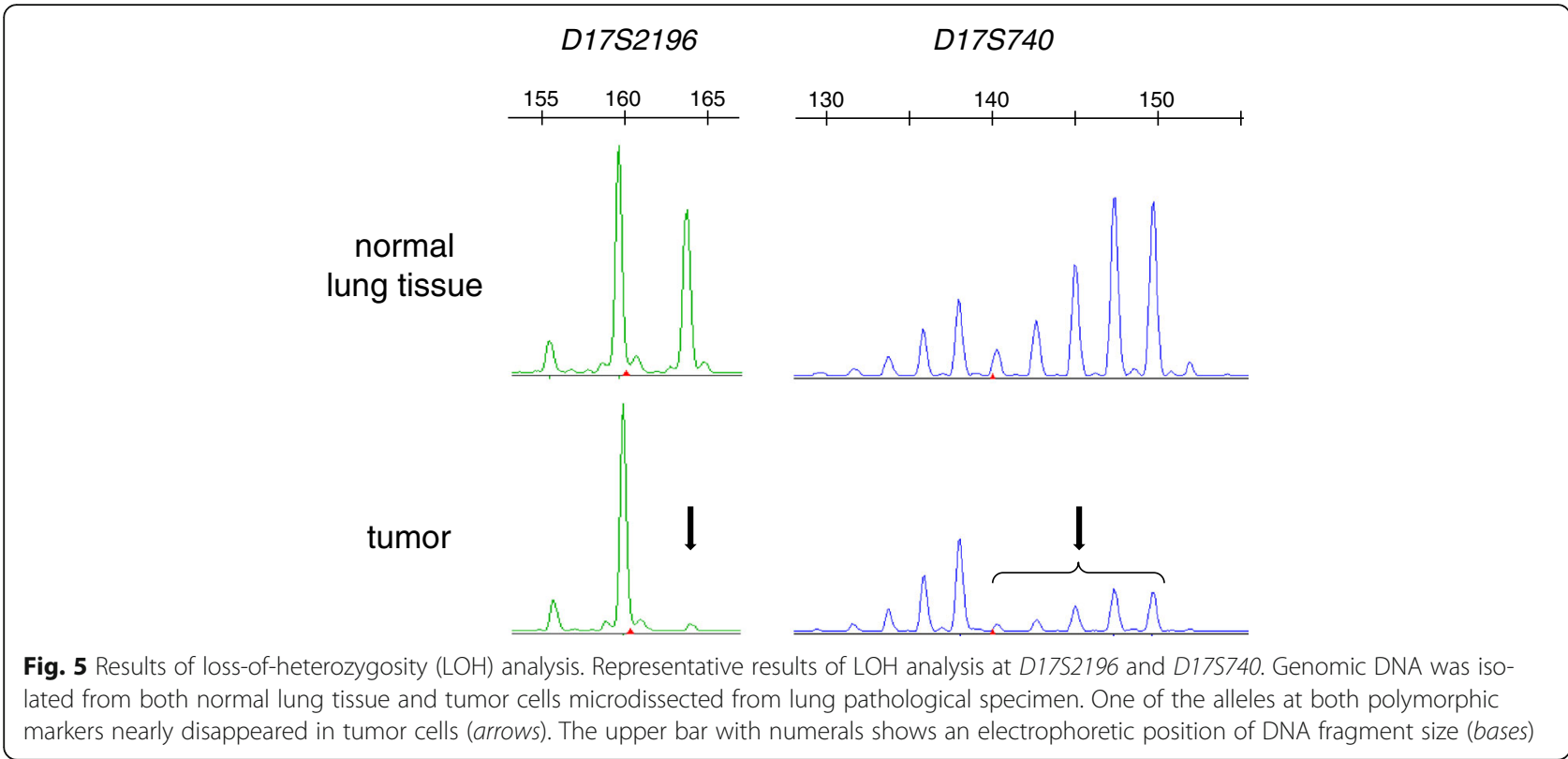

caused by a germline RET mutation [2]. In this context, the present family may represent a de novo FLCN mutation that emerged in the patient's mother and grandmother who may have descended from a family with an unknown cancer propensity.

\section{Conclusions}

To our knowledge, this is the first report of CCST of the lung in a patient with BHD syndrome and may suggest that folliculin and mTORC1 are closely associated with the tumorigenesis of this rare affliction.

\section{Abbreviations}

BHDS: Birt-Hogg-Dubé syndrome; CCST: Clear cell sugar tumor;

CT: Computer-assisted tomography; FLCN: Folliculin; H\&E: Hematoxylin and eosin; LOH: Loss of heterozygosity; mTOR: Mechanistic target of rapamycin; mTORC1: Mechanistic target of rapamycin complex-1; PAS: Periodic acidSchiff; PEComa: Perivascular epithelioid cell tumors; PTX: Pneumothorax:

TSC: Tuberous sclerosis complex; $a-S M A$ : $a-s m o o t h$ muscle actin

\section{Acknowledgments}

We thank the patient and her family for their contribution to this case report. We also thank Ms. Phyllis Minick for excellent assistance in the review of English.

\section{Funding}

This study was supported by a Grant-in-Aid for Scientific Research No. 22790767 (Kikkawa M), No. 24591177 (Kikkawa M), and No. 25670402 (Seyama K) from the Ministry of Education, Culture, Sports, Science, and Technology, Japan.

\section{Availability of data and material}

Data included in this study are freely available and can be obtained by contacting the corresponding author.

\section{Authors' contributions}

The work presented here was carried out in collaboration between all authors. YGN and MK performed mutation analysis of the FLCN gene. HT and KS performed clinical assessment, diagnostic testing and patient management. RM performed the operation for the lung tumor and patient management. YH, TH, and EK performed $\mathrm{LOH}$ analysis of the FLCN-, TSC1-, and TSC2-associated regions. TK, SK, TH, and KM performed histopathological and immunohistochemical examinations for the lung tumor. SK, TH, and TK made a diagnosis based on pathological findings. TK and KS defined the study design. KS and KT supervised this case. YGN drafted the manuscript. KS supervised and finalized the manuscript. All authors read and approved the final manuscript.

\section{Competing interests}

The authors declare that they have no competing interests.

\section{Consent for publication}

We have obtained written informed consent from the patient for publication of this case report and any accompanying images.

\section{Ethics approval and consent to participate}

This study was approved by the Institutional Review Board of Juntendo University Hospital and performed in accordance with the Declaration of Helsinki. We have obtained written informed consent from the patient for publication of this case report and any accompanying images. A copy of the written consent is available for review by the Editor of this journal.

\section{Author details}

${ }^{1}$ Divisions of Respiratory Medicine, Juntendo University Faculty of Medicine and Graduate School of Medicine, 3-1-3, Hongo, Bunkyo-Ku, Tokyo 113-8431, Japan. ${ }^{2}$ Department of Pathology, Japanese Red Cross Medical Center, 4-1-22, Hiroo, Shibuya-Ku, Tokyo 150-8935, Japan. ${ }^{3}$ Departments of Pathology, JCHO Tokyo Yamate Medical Center, 3-22-1 Hyakunin-cho, Shinjuku-Ku, Tokyo 169-0073, Japan. ${ }^{4}$ Human Pathology, Juntendo University Faculty of Medicine and Graduate School of Medicine, 3-1-3, Hongo, Bunkyo-Ku, Tokyo 113-8431, Japan. ${ }^{5}$ Respiratory Medicine, JCHO Tokyo Yamate Medical Center, 3-22-1 Hyakunin-cho, Shinjuku-Ku, Tokyo 169-0073, Japan. ${ }^{6}$ Thoracic Surgery, JCHO Tokyo Yamate Medical Center, 3-22-1 Hyakunin-cho, Shinjuku-Ku, Tokyo 169-0073, Japan. 'Laboratory of Proteomics and Biomolecular Science, Biomedical Research Center, Juntendo University Faculty of Medicine and Graduate School of Medicine, 3-1-3, Hongo, Bunkyo-Ku, Tokyo 113-8431, Japan. ${ }^{8}$ The Study Group of Pneumothorax and Cystic Lung Diseases, 4-8-1 Seta, Setagaya-Ku, Tokyo 158-0095, Japan.

Received: 19 November 2015 Accepted: 15 November 2016 Published online: 21 November 2016 


\section{References}

1. Hornstein OP, Knickenberg M. Perifollicular fibromatosis cutis with polyps of the colon-a cutaneo-intestinal syndrome sui generis. Arch Dermatol Res. 1975:253:161-75.

2. Birt AR, Hogg GR, Dube WJ. Hereditary multiple fibrofolliculomas with trichodiscomas and acrochordons. Arch Dermatol. 1977:113:1674-7.

3. Nickerson ML, Warren MB, Toro JR, Matrosova V, Glenn G, Turner ML, et al. Mutations in a novel gene lead to kidney tumors, lung wall defects, and benign tumors of the hair follicle in patients with the Birt-Hogg-Dube syndrome. Cancer Cell. 2002;2:157-64.

4. Warren MB, Torres-Cabala CA, Turner ML, Merino MJ, Matrosova VY, Nickerson ML, et al. Expression of Birt-Hogg-Dube gene mRNA in normal and neoplastic human tissues. Mod Pathol. 2004;17:998-1011.

5. Sarbassov DD, Ali SM, Sabatini DM. Growing roles for the mTOR pathway. Curr Opin Cell Biol. 2005:17:596-603.

6. Brugarolas J, Kaelin Jr WG. Dysregulation of HIF and VEGF is a unifying feature of the familial hamartoma syndromes. Cancer Cell. 2004:6:7-10.

7. Inoki K, Corradetti MN, Guan KL. Dysregulation of the TSC-mTOR pathway in human disease. Nat Genet. 2005;37:19-24.

8. Cheadle JP, Reeve MP, Sampson JR, Kwiatkowski DJ. Molecular genetic advances in tuberous sclerosis. Hum Genet. 2000;107:97-114.

9. Hemminki A, Avizienyte $E$, Roth $S$, Loukola $A$, Aaltonen $L A$, Järvinen $H$, et al. A serine/threonine kinase gene defective in Peutz-Jeghers syndrome. Duodecim. 1998;114:667-8

10. Eng C. PTEN: one gene, many syndromes. Hum Mutat. 2003;22:183-98.

11. Tsun ZY, Bar-Peled L, Chantranupong L, Zoncu R, Wang T, Kim C, et al. The folliculin tumor suppressor is a GAP for the RagC/D GTPases that signal amino acid levels to mTORC1. Mol Cell. 2013;52:495-505.

12. Liebow AA, Castleman B. Benign clear cell ("sugar") tumors of the lung. Yale J Biol Med. 1971;43:213-22.

13. Armah HB, Parwani AV. Perivascular epithelioid cell tumor. Arch Pathol Lab Med. 2009:133:648-54.

14. Bonetti F, Pea M, Martignoni G, Doglioni C, Zamboni G, Capelli P, et al. Clear cell ("sugar") tumor of the lung is a lesion strictly related to angiomyolipomathe concept of a family of lesions characterized by the presence of the perivascular epithelioid cells (PEC). Pathology. 1994;26:230-6.

15. Flieder DB, Travis WD. Clear cell "sugar" tumor of the lung: association with lymphangioleiomyomatosis and multifocal micronodular pneumocyte hyperplasia in a patient with tuberous sclerosis. Am J Surg Pathol. 1997:21:1242-7.

16. Pan CC, Chung MY, Ng KF, Liu CY, Wang JS, Chai CY, et al. Constant allelic alteration on chromosome 16p (TSC2 gene) in perivascular epithelioid cell tumour (PEComa): genetic evidence for the relationship of PEComa with angiomyolipoma. J Pathol. 2008:214:387-93.

17. Gunji Y, Akiyoshi T, Sato T, Kurihara M, Tominaga S, Takahashi K, et al. Mutations of the Birt Hogg Dube gene in patients with multiple lung cysts and recurrent pneumothorax. J Med Genet. 2007;44:588-93.

18. Khoo SK, Kahnoski K, Sugimura J, Petillo D, Chen J, Shockley K, et al. Inactivation of BHD in sporadic renal tumors. Cancer Res. 2003;63:4583-7.

19. Travis WD BE, Muller-Hermelink HK, Harris CC, editors. World Health Organization Classification of Tumours. Pathology and Genetics of Tumours of the Lung. Lyon: IARC Press; 2004

20. Argani P, Aulmann S, Illei PB, Netto GJ, Ro J, Cho HY, et al. A distinctive subset of PEComas harbors TFE3 gene fusions. Am I Surg Pathol. 2010:34:1395-406

21. Folpe AL, Mentzel T, Lehr HA, Fisher C, Balzer BL, Weiss SW. Perivascular epithelioid cell neoplasms of soft tissue and gynecologic origin: a clinicopathologic study of 26 cases and review of the literature. Am J Surg Pathol. 2005;29:1558-75.

22. Gaffey MJ, Mills SE, Zarbo RJ, Weiss LM, Gown AM. Clear cell tumor of the lung. Immunohistochemical and ultrastructural evidence of melanogenesis, Am J Surg Pathol. 1991;15:644-53.

23. Gal AA, Koss MN, Hochholzer L, Chejfec G. An immunohistochemical study of benign clear cell ('sugar') tumor of the lung. Arch Pathol Lab Med. 1991;115:1034-8

24. Petit CS, Roczniak-Ferguson A, Ferguson SM. Recruitment of folliculin to lysosomes supports the amino acid-dependent activation of Rag GTPases. J Cell Biol. 2013;202:1107-22

25. Adachi $Y$, Kitamura $Y$, Nakamura $H$, Taniguchi $Y$, Miwa $K$, Horie $Y$, et al. Benign clear (sugar) cell tumor of the lung with CD1a expression. Pathol Int. 2006;56:453-6.
26. Khoo SK, Bradley M, Wong FK, Hedblad MA, Nordenskjöld M, Teh BT. BirtHogg-Dube syndrome: mapping of a novel hereditary neoplasia gene to chromosome 17p12-q11.2. Oncogene. 2001;20:5239-42.

27. Roth JS, Rabinowitz AD, Benson M, Grossman ME. Bilateral renal cell carcinoma in the Birt-Hogg-Dube syndrome. J Am Acad Dermatol. 1993;29:1055-6.

28. Toro JR, Glenn G, Duray P, Darling T, Weirich G, Zbar B, et al. Birt-HoggDube syndrome: a novel marker of kidney neoplasia. Arch Dermatol. 1999;135:1195-202.

29. Nahorski MS, Lim DH, Martin L, Gille JJ, McKay K, Rehal PK, et al. Investigation of the Birt-Hogg-Dube tumour suppressor gene (FLCN) in familial and sporadic colorectal cancer. J Med Genet. 2010;47:385-90.

30. Kashiwada T, Shimizu H, Tamura K, Seyama K, Horie Y, Mizoo A. Birt-HoggDube syndrome and familial adenomatous polyposis: an association or a coincidence? Intern Med. 2012;51:1789-92.

\section{Submit your next manuscript to BioMed Central and we will help you at every step:}

- We accept pre-submission inquiries

- Our selector tool helps you to find the most relevant journal

- We provide round the clock customer support

- Convenient online submission

- Thorough peer review

- Inclusion in PubMed and all major indexing services

- Maximum visibility for your research

Submit your manuscript at www.biomedcentral.com/submit
Biomed Central 